\title{
Una agricultura insostenible y la crisis del barbecho: el caso de los agricultores del valle de los ríos Apurímac y Ene, VRAE ${ }^{1}$
}

\author{
Eduardo Bedoya Garland \\ FLACSO Quito \\ ebedoyagarland20@gmail.com \\ Carlos Eduardo Aramburú \\ PUCP Lima \\ caramburu@pucp.pe
}

\section{Zulema Burneo}

Antropóloga

zburneo@gmail.com

\section{RESUMEN}

Este artículo sobre los agricultores cocaleros del valle de los ríos Apurímac y Ene (VRAE), demuestra que la abundancia de «purmas» o bosque secundario se debe a la sobreutilización de los suelos donde se cultiva la coca, a la utilización excesiva de insumos modernos o agroquímicos en dichas plantaciones y al manejo tradicional o empírico del cultivo del cacao y otros sembríos transitorios. La alta correlación entre el tamaño del predio y el área en «purmas» es un fiel reflejo de la crisis del barbecho en el VRAE. La indicada crisis, sin embargo, no es más que un resultado de la insostenibilidad de este sistema agrícola. Los factores más importantes de dicha crisis son, por un lado, una intensificación en el cultivo de la coca que degrada el suelo, y por otro, un uso extensivo del suelo sin un cambio

\footnotetext{
1 Desde el año 2012, al territorio que comprende el VRAE se le ha sumado la región del río Mantaro. Por ello actualmente se le denomina VRAEM (valles del río Apurímac, Ene y Mantaro). Debido que nuestro estudio fue realizado entre 2001 y 2004, preferimos mantener las siglas de VRAE.
} 
tecnológico en el caso de los cultivos legales. En los dos casos, el efecto global es la destrucción de los bosques, la deforestación y el empobrecimiento del suelo.

Palabras clave: coca, deforestación, agricultura sostenible, Amazonía, crisis del barbecho.

\section{Unsustainable agriculture and the fallow crisis: The case of farmers in the Apurimac and the Ene River Valley, VRAE}

SUMMARY

This article is dedicated to the coca farmers of the VRAE. It shows that the abundance of "purmas» or secondary forest is due to the overuse of soils where coca is cultivated, the excessive use of modern or agrochemical inputs in these plantations and the traditional or empirical management of the cultivation of cacao and other annual crops. The high correlation between plot size and area in "purmas» is a true reflection of the fallow crisis in the VRAE. This crisis, however, is a result of the unsustainability of the aforementioned agricultural systems. The most important factors of this crisis are, on the one hand, an agricultural intensification of the cultivation of coca that degrades the soil and, on the other hand, an extensive use of the soil without a technological change in the case of legal crops. In both cases, the overall effect is the destruction of forests, deforestation and soil impoverishment.

Keywords: coca, deforestation, sustainable agriculture, Amazon, fallow crisis. 


\section{INTRODUCCIÓN}

La agricultura de tala, rozo y quema, también conocida como agricultura migratoria o itinerante, practicada por agricultores colonos en la Amazonía peruana, boliviana, ecuatoriana y brasileña, muy distinta de la horticultura tradicional indígena, siempre ha sido materia de interés, reflexión y controversia académica, científica y política ${ }^{2}$. Contrariamente a la percepción generalizada, el referido sistema agrícola sigue siendo utilizado por unidades familiares de agricultores, especialmente migrantes o colonos, en muchas regiones tropicales de América Latina, África y Asia (Gómez de la Torre, Anda y Bedoya, 2017; Caldas et al., 2007; Aldrich et al., 2006; Brondizio, 2009; Perz et al., 2005; Perz, 2002; Bilsborrow, 1997) ${ }^{3}$. En la actualidad, como consecuencia del calentamiento global derivado del cambio climático, la denominada agricultura de roza y quema ha adquirido nuevamente un interés inusitado, especialmente debido a su impacto en la deforestación del bosque tropical y su contribución al propio cambio climático.

En el Perú, la información disponible de ACA y Conservación Amazónica (ACCA) recientemente publicados (ACA-ACCA, 2016) señala que entre 2013 y 2015 un mínimo del $71 \%$ de la deforestación amazónica ha sido provocada por agricultores que manejan predios o parcelas de menos de cinco hectáreas y alrededor del 19\% restante por predios medianos cuyo tamaño fluctúa entre 5,1 y 50 hectáreas. En este último grupo también se practica la denominada agricultura

2 La horticultura o agricultura de rozo y quema o itinerante es una forma antigua de agricultura de subsistencia practicada en zonas de bosques tropicales. Consiste en la deforestación y tala de terrenos muy pequeños, seguida por la quema de la vegetación remanente para la fertilización del suelo con las cenizas, lo que permite un uso temporal (dos a cuatro años) para cultivos diversificados hasta agotarse la fertilidad natural del suelo (Watters, 1971). La horticultura normalmente viene acompañada de la caza, pesca y recolección entre los grupos indígenas.

3 Para el tema de la agricultura migratoria, ver también Helmut (2002, p. 145), Yanggen (1999) y Banco Mundial (2000). 
de tala, rozo y quema, con tasas anuales incluso mayores que en las unidades más pequeñas (Bedoya, 2003; Bedoya y Ramírez, 2001; Bedoya, 1999; y Bedoya y Klein, 1996). Cabe recalcar que dicha modalidad de agricultura se diferencia muy claramente de las prácticas productivas de las poblaciones indígenas amazónicas. En ese sentido, en numerosas ocasiones se ha generado confusión y equívoco con la horticultura tradicional desarrollada por las indicadas sociedades nativas amazónicas, la cual se basa en una práctica asociada a la caza, pesca y recolección, y en general, al uso más sostenible de los recursos naturales (Cairns, 2015).

Un ejemplo de la expansión de la agricultura migratoria en la Amazonía peruana es el caso del VRAE. Esta región es considerada como la segunda zona en cuanto a producción cocalera del Perú. Se localiza en la selva alta, concretamente en la intersección de los departamentos de Cusco, Ayacucho y Junín. El ecosistema del mencionado valle se clasifica como selva alta subtropical y se ubica entre los 500 a 1500 metros sobre el nivel del mar (MINAM et al., 2009, p. 32). El VRAE constituye un espacio donde predominan los agricultores de rozo y quema dedicados al cultivo de la coca (Erythroxylon coca) para el narcotráfico y otros productos como el cacao (Theobroma cacao), café (Coffea arábica), maíz (Zea mays), plátano (Musa paradisiaca) etc. (Bedoya, 2003).

\section{OBJETIVOS Y METODOLOGÍA}

El sistema agrícola de rozo y quema practicado por los productores del VRAE seguía reproduciéndose entre los años 2001 y 2004. Desde entonces han ocurrido cambios en esta modalidad de uso del suelo, pero estos han sido realmente menores. Para ilustrar estos cambios, aprovechamos un estudio realizado hace catorce años y que en este documento utilizamos como testimonio histórico ${ }^{4}$. Entre los años 2001 y 2002 realizamos numerosas visitas de campo al VRAE, donde se coordinaron estudios sobre la economía cocalera de pequeños agricultores de la región. En un primer caso, el año 2001, se aplicó una encuesta a los agricultores en el distrito de Santa Rosa y la zona de Palmapampa, localizada en el distrito de San Miguel, en la provincia de La Mar, Ayacucho (Bedoya, 2003; Bedoya y

\footnotetext{
La primera investigación fue realizada a finales de febrero de 2001 en el valle de los ríos Apurímac y Ene (VRAE), a pedido del Consorcio de Investigación Económica y Social (CIES) y de Winrock (institución responsable de las labores de desarrollo alternativo en el VRAE) y con el apoyo de USAID. Los datos y resultado del estudio fueron originalmente publicados por CIES en 2003 (Bedoya, 2003). El economista Walter Ramírez tuvo un papel muy destacado en dicho estudio.
} 
Ramírez, 2001; Ramírez, 2001). La encuesta abarcó a 120 agricultores, de los cuales 83 eran cocaleros y 37 no lo eran. Seguidamente, entre 2001 y 2004 se realizaron veinticinco entrevistas a profundidad a varias familias cocaleras. $\mathrm{La}$ abrumadora mayoría de los agricultores eran bilingües quechua-hablantes nacidos en comunidades campesinas altoandinas de Huanta, La Mar y Huamanga, en el departamento de Ayacucho ${ }^{5}$. Dicha metodología permitió cotejar la información estadística de las encuestas con la información más cualitativa proporcionada gentilmente por los agricultores. Resulta importante recalcar que el estudio se centra en los primeros años del presente siglo. En ese sentido, constituye un esfuerzo de reconstruir la información recopilada aquellos años, como también su contextualización sobre la base de la literatura de entonces.

En dichas entrevistas obtuvimos una percepción más o menos clara sobre las estrategias productivas de los colonos y su impacto en la deforestación. La combinación de modalidades productivas algunas basadas en un uso intensivo del suelo acompañadas de cambio tecnológico y otras que recurren a formas de uso muy extensivo del suelo, tiene como propósito reducir el riesgo en un contexto donde el cultivo de la coca está rodeado de incertidumbres muy grandes. Sin embargo, en términos ambientales tal estrategia no ha tenido éxito. Tanto en un caso como en otro, las externalidades e impactos sobre los bosques son significativas. En ese contexto nuestra hipótesis principal es que los sistemas agrícolas en esta zona tropical son, a mediano plazo, insostenibles.

En este estudio se demuestra que la abundancia de «purmas» en numerosas ocasiones de helechos en el VRAE, se debe a la sobreutilización del suelo donde se siembra y cosecha la coca, a la utilización excesiva de insumos modernos o agroquímicos en dichas plantaciones así como al mantenimiento tradicional o empírico del cultivo del cacao y otros sembríos transitorios. La alta correlación entre tamaño del predio y el área en «purmas» es un fiel reflejo de la crisis del barbecho en el VRAE. La indicada crisis no es más que un resultado de la insostenibilidad de estos sistemas agrícolas. Los factores más importantes de dicha crisis son, por un lado, una intensificación agrícola en el cultivo de la coca que

\footnotetext{
La edad promedio de los jefes de familia de las unidades agrícolas estudiadas era de cuarenta años: un $85 \%$ eran hombres y un $15 \%$ eran mujeres. Para el $100 \%$ de los jefes de familia entrevistados, la agricultura dentro de su unidad agropecuaria era la principal actividad, lo mismo que para un $91 \%$ de los familiares. Una característica adicional importante es que solo el $18 \%$ de los agricultores pescaba y solo un $12 \%$ realizaba actividades eventuales de caza, lo cual los diferencia de grupos nativos en la Amazonía, que suelen tener una diversificación productiva mucho mayor y una dependencia mayor con los recursos del bosque (Bedoya, 1995).
} 
degrada el suelo, y por otro, un uso extensivo del suelo sin un cambio tecnológico en el caso de los cultivos legales y sin un adecuado período de descanso del suelo, que posibilite la regeneración de la fertilidad natural del suelo. En los dos casos, el efecto global es la destrucción de los bosques, la deforestación y el empobrecimiento del suelo. El texto se estructura en un conjunto de secciones; la primera ofrece una explicación de la racionalidad del cultivo de la coca, luego se presenta una descripción del VRAE como frente de deforestación seguida de un análisis detallado de los procesos de intensificación y extensificación, como procesos que contribuyen a la insostenibilidad de los sistemas productivos. Finalmente se presentan algunas conclusiones sobre la evolución de los sistemas agrícolas en esta zona tropical del Perú.

\section{LA RACIONALIDAD DE LA COCA Y LOS CULTIVOS TRANSITORIOS EN LA AGRICULTURA FAMILIAR EN EL VRAE}

Las migraciones de campesinos altoandinos al VRAE datan de principio del siglo pasado. En un inicio fueron promovidas o inducidas por las Leyes de Montaña, que provocaron colonizaciones espontáneas de carácter permanente o estacional entre campesinos minifundistas cuyos terrenos en las provincias de La Mar, Huamanga y Huamanga estaban degradados por lo que, buscaban tierras abundantes de libre disponibilidad (Espinosa, 2009, pp. 141-142; Durand, 2005, p. 111; Sala i Vila, 2001, pp. 157, 165-166). Sin embargo en general, durante gran parte del siglo pasado, el VRAE experimentó migraciones periódicas, alentadas por la construcción de caminos de penetración (Aramburú, 1982, p. 18) y por la demanda de productos específicos como la extracción de cube y barbasco en la década de 1950 (Durand, 2005, p. 111); el café en los años 1960; el cacao en 1970 y 1980, y finalmente la coca para el narcotráfico y las movilizaciones forzosas escapando de Sendero Luminoso entre 1990 y 2000 (Diez, 2003, p. 97).

Ahora bien, los procesos agrícolas y productivos en el VRAE son bastante complejos en su origen. La reproducción de la práctica de la agricultura de rozo y quema entre los agricultores cocaleros del VRAE es en gran medida consecuencia de sus condiciones económicas y de la forma como los productores ejecutan sus estrategias de sobrevivencia en un contexto altamente riesgoso y lleno de incertidumbres, resultado de la ilegalidad del cultivo de la coca. Según el estudio realizado en 2001, aproximadamente el $47 \%$ de los ingresos monetarios agrícolas proviene de la coca, frente al $22 \%$ del cacao o el café y un $31 \%$ de venta de animales y el trabajo asalariado agrícola (Ramírez, 2001; Bedoya y Ramírez, 2001). 
Los altos ingresos monetarios del cultivo de coca se derivan evidentemente de su transformación en pasta básica de cocaína y su venta para fines del narcotráfico. La coca cumple en la región tropical múltiples funciones; como caja chica, para cubrir gastos cotidianos familiares y los costos de producción de otros cultivos lícitos, como el café o cacao, debido a que se cosecha cada tres meses. Asimismo, sirve como caja grande en función de su alta rentabilidad, por lo que se usa para cubrir gastos de educación de los hijos, instalar un negocio en el pueblo, compra de bienes durables, etc. Las múltiples cosechas anuales de las hojas de coca generan ingresos monetarios no solo frecuentes sino difícilmente reemplazables. Inicialmente, los productores más jóvenes del VRAE suelen deforestar un predio, y de inmediato siembran cultivos anuales de autoconsumo, conjuntamente con un tercio de hectárea de coca, la cual rinde sus primeras cosechas al año de su siembra.

La funcionalidad de la coca no se restringe a la necesidad de ingresos monetarios. En primer lugar, la coca tiene un poder simbólico muy significativo (Mayer, 2004; Burchard, 1974, pp. 242, 246-247). En segundo lugar, la coca también se articula con la economía no monetaria del intercambio o trueque con las comunidades altoandinas (Burchard, 1974, p. 248). Ello ocurre con el 9\% de la cosecha anual de los cocales, según cálculos realizados por instituciones del Estado al momento del estudio (Bedoya y Ramírez, 2001). Dicho porcentaje permite al agricultor articularse con una economía de reciprocidad y una densa red de relaciones sociales tradicionales andinas. Sin embargo, la articulación con la red de reciprocidad andina no debe generar una imagen idílica de los cocaleros como campesinos supuestamente tradicionales articulados a una economía comunal andina y donde la coca funcionaría dentro de un circuito no monetario únicamente como moneda de intercambio de productos y como medio de pago a trabajadores. El hecho de que un porcentaje de la coca sea utilizado dentro de un espacio de carácter no monetarizado y muy delimitado no significa que no sea mercancía. Todo lo contrario. La mayor parte de la cosecha de la coca es comercializada por el narcotráfico o transformada directamente a pasta básica de cocaína por los mismos agricultores. La coca es sobre todo un cultivo altamente comercial, dependiente de los vaivenes internacionales de la oferta y demanda de la cocaína, de las condiciones políticas e institucionales en las que se cultiva y de la violencia que ello implica. Se trata de una auténtica commodity global, vendida con valor agregado en el mercado internacional pero con el riesgo que resulta de su ilegalidad. En ese sentido, los agricultores cocaleros son productores sumamente mercantilizados, aunque también articulados a una economía andina tradicional. 
En ese contexto, la hoja de coca y la pasta básica son productos altamente riesgosos y las externalidades sociales y ambientales que generan son cuantiosas. Se estima que durante 2001, en el procesamiento de la pasta básica de cocaína, se utilizaron en el VRAE las siguientes cantidades de insumos: más de un millón de galones de kerosene, decenas de miles de galones de ácido sulfúrico y de ácido clorhídrico, miles de toneladas métricas de carbonato de calcio y decenas de toneladas métricas de carbonato de sodio. A ello se suman los efectos colaterales que provoca el cultivo de la coca sobre los bosques. La comercialización y traslado de la pasta básica de cocaína requiere deforestar para construir pistas de aterrizaje clandestinas.

El cultivo de la coca también demanda desboscar para sembrar cultivos de autoconsumo y así alimentar a los trabajadores y a todos los miembros de la familia. Los cultivos transitorios o anuales, como el maíz, arroz y frijol, son cultivados bajo el régimen de lluvias en un terreno de una hectárea o hectárea y media. Con excepción de la yuca, que es muy comercializada en la zona, el objetivo de dichos productos es cubrir las necesidades alimenticias familiares y de los trabajadores, que son reclutados desde las provincias de altura para las actividades de mantenimiento y cosecha de la coca, y en menor medida, para plantaciones como el cacao. A los productores del VRAE todavía les resulta comparativamente más barato cultivar algunos productos para el autoconsumo que adquirirlos en el mercado. Es lo que Chevalier (1982, p. 120) denomina como «maximización de lo concreto», a través del consumo directo de «mercancías de subsistencia». Los productores en el VRAE, como muchos otros de la selva amazónica, maximizan de forma más eficiente el valor de un producto consumiéndolo directamente, antes que adquirirlo a un costo muy alto en el mercado. Para ello disponen de tierra y mano de obra libre sin ningún tipo de restricciones. Algunos agricultores permiten que los jornaleros que migran temporalmente desde las partes altas desmonten ciertas partes de su predio para sembrar cultivos transitorios, cuya cosecha luego es trasladada a sus comunidades en la sierra. Ello constituye una forma de pago que los agricultores practican con los jornaleros eventuales. En su conjunto, toda esta estrategia refuerza la expansión de una agricultura de rozo y quema y contribuye a la destrucción de bosques.

A los cultivos transitorios de autoconsumo se suma una serie de plantaciones de plátano, cítricos diversos, piña y otros, cada uno con diferentes períodos de maduración y duración, algunos de ellos de carácter semipermanente. Sin embargo, este tipo de cultivos tampoco frena la agricultura de rozo y quema o reduce la deforestación, dado que son cultivados de manera muy empírica para el autoconsumo familiar. Ello también es consecuencia de que muchos de los 
cocaleros del VRAE ubican sus predios en zonas muy alejadas de los caminos troncales con el objetivo de alejarse de las labores de erradicación e interdicción. En las zonas cocaleras sucede un fenómeno curioso y totalmente inverso a lo que enseña la geografía económica, y es que los productores agrícolas se alejan lo más posible de toda vía de transporte terrestre para así ocultar sus plantaciones de coca, lo cual dificulta el traslado y comercialización de productos lícitos que requieren un transporte rápido por su carácter perecible, tales como el plátano, la piña y otras frutas (Aramburú, 1984).

\section{EL VRAE COMO FRENTE DE DEFORESTACIÓN}

Como producto de la dinámica productiva descrita, la deforestación en dicha región ha sido muy intensa y sostenida sobre todo en los últimos quince años del siglo pasado; es decir, desde mediados de la década de 1980. Inicialmente ello se debió a la dinámica de expansión del cultivo del cacao, luego de la coca $\mathrm{y}$ de los cultivos anuales asociados a dichas plantaciones, sembrados por razones de subsistencia, y finalmente, en el período más reciente, al nuevo impulso que dan el Estado y la cooperación bilateral (USAID) al cultivo del cacao como actividad alternativa al cultivo de la hoja de coca. En ese sentido, sin embargo, si bien el VRAE ha soportado intensos procesos de deforestación desde la década de 1980, la colonización es bastante más antigua, tal como se ha descrito. El valle ha experimentado sucesivas oleadas migratorias y la pequeña propiedad, o incluso el minifundismo de menos de cinco hectáreas está bastante difundido (Bedoya, 2003).

Actualmente, el VRAE es considerado como uno de los denominados frentes de deforestación de la Amazonía (MINAM et al., 2015. p. 32), debido a la intensidad de destrucción del bosque de los últimos años. La zona del VRAE localizada en el departamento de Junín, se caracteriza por sus niveles extremadamente altos de destrucción boscosa; la del Cusco presenta niveles de deforestación entre muy altos y medianos, y la de Ayacucho entre medianos y bajos (MINAM et al., 2015, p. 27). El VRAE cubre una superficie total de 1493118 hectáreas, de las cuales un $92,96 \%$, son tierras de protección y de aptitud forestal, 3,62\%, de su superficie es considerada de aptitud para pastoreo, $2,76 \%$ son aptas para cultivo permanentes y solo 0,66\% para cultivos transitorios o anuales (Martínez, 2010, p. 7). En la margen derecha de los ríos Ene y Apurímac se localizan tres zonas naturales protegidas, donde residen poblaciones nativas: la Reserva Comunal Ashaninka, el Parque Nacional Otishi y la Reserva Comunal Machiguenga. 
En 2001, al momento del estudio, se deforestaron 7424 hectáreas, en dicho año y para esa fecha ya se había deforestado un total de 254480 hectáreas de bosque primario, lo cual sucedió a diferentes ritmos desde 1975. Ello representaba el $17 \%$ de todo el territorio del VRAE ${ }^{6}$. Algunos autores estiman que, de dicho total, un aproximado de 2500 ha se deben a la apertura de chacras para la coca del narcotráfico. En otras palabras, cada año dos tercios habrían sido deforestados principalmente para cultivos lícitos, tales como el cacao, café y cultivos anuales y un tercio para la coca (MINAGRI, 2012, p. 17). No obstante, si es que se analiza este fenómeno recurriendo a las entrevistas con los agricultores y a otras fuentes de carácter secundario que estudian la dinámica regional de cambio de uso del suelo, resulta claro que el cultivo de la coca tiene indirectamente una importante cuota de responsabilidad en el proceso de deforestación.

Por último, un rasgo notorio de las zonas donde se realizó el estudio es la casi desaparición del bosque virgen o primario. En ambas zonas, únicamente el $8 \%$ de los terrenos de los predios estaban cubiertos por bosques primarios y un $27 \%$ por «purmas» o verdipas (nombre local más utilizado), es decir, por bosques secundarios. Por la información de campo, estimamos que tres cuartos de la deforestación se produce sobre este último tipo de vegetación. El término «purma»a menudo es usado por agricultores selváticos en el Perú para referirse a los bosques secundarios, sobre todo cuando se trata de bosques secundarios de más de cinco a ocho años de crecimiento. Smith (1997, p. 3) definió al bosque secundario como aquel de «vegetación leñosa de carácter sucesional que se desarrolla sobre tierras cuya vegetación original fue destruida por actividades humanas». A continuación nos centramos en comprender los procesos correspondientes a la racionalidad productiva de la agricultura migratoria o agricultura de rozo y quema y su impacto en la destrucción de bosques, a partir de las estrategias de sobrevivencia y las formas de intensificación de uso del suelo de los colonos de la zona.

Como consecuencia de dicho proceso destructivo, cada vez más el ecosistema del VRAE se asemeja a una savanna tropical y menos a un bosque subtropical denso, al menos en el caso del territorio que fue materia de investigación. Dicho territorio se parece a un mosaico de fragmentos de bosque, principalmente bosques secundarios o «purmas», en diferentes estados de sucesión y con distintos tipos de configuración, intercalados con terrenos cultivados. Los nuevos focos de deforestación en el VRAE se localizan en zonas más alejadas, en dirección sureste del valle.

6 Entre los años 2001 y 2013, un total de otras 30902 hectáreas de bosque prístino y secundario fueron desboscadas, lo cual significó que continuó la destrucción, sumando un 19,20\% del total del territorio del VRAE (MINAM, 2015). 


\section{LA INTENSIFICACIÓN DEL USO DEL SUELO EN EL VRAE}

Los sistemas agrícolas en el VRAE se caracterizan por dos formas de ocupación del espacio. En primer lugar, por una agricultura de rozo, quema y rotación de suelos dentro de una misma parcela agropecuaria, dependiente de las lluvias y con un uso empírico o muy bajo de insumos modernos (fertilizantes, pesticidas y fungicidas). Una segunda modalidad es conducida por agricultores invasores, quienes siembran dos o tres años, y luego, al enfrentar rendimientos decrecientes, se trasladan a otra zona donde establecen una nueva parcela familiar. Este tipo de agricultura es denominado por el informe de MINAM (2015, pp. 35-36) como «agricultura tradicional a pequeña escala». Otros autores la han denominado «agricultura migratoria» o «agricultura comercial de rozo y quema» (Watters, 1971).

Según la información del estudio, en 2001 alrededor del 55\% de los cocaleros y alrededor de $47 \%$ de los no cocaleros practicaban rotación de suelos o agricultura migratoria dentro del predio. Es decir, alrededor del 53\% de los productores entrevistados seguía practicando este tipo de agricultura. Wachhlotz (1996, pp. 16-18) realizó un estudio cinco años antes en la zona del VRAE y llegó a conclusiones bastante similares. Según dicho autor, el 55\% de los productores que conducían alrededor de cinco hectáreas en promedio, manejaban plantaciones de coca y además sembraban otros cultivos, y practicaban la agricultura migratoria al interior de sus propios predios agrícolas. Otro $40 \%$ que tenía predios con un promedio de 15,8 hectáreas, conducía un sistema diversificado de cultivos que incluía más hectáreas de cacao y recurría a la práctica de trasladarse continuamente dentro de su unidad agrícola (p. 18).

El problema radica en que la agricultura migratoria practicada por colonos o sus descendientes es un sistema que induce a una deforestación continua, incluso en predios relativamente pequeños. Un posible marco analítico para entender lo que sucede en el VRAE son los argumentos de Boserup (1965) sobre crecimiento poblacional e intensificación agrícola. La mencionada economista basa su análisis en los procesos históricos de intensificación del uso del suelo como consecuencia del incremento de la presión población sobre los recursos naturales, lo cual puede estimarse por un aumento en la densidad demográfica. Conforme se eleva la densidad poblacional, las sociedades rurales se ven obligadas a intensificar el uso del suelo introduciendo innovaciones tecnológicas con el propósito de obtener más alimentos (Boserup, 1965). Usualmente ello implica reducir tanto el número de años dedicados al descanso del suelo como la cantidad de tierras que son abandonadas para su regeneración natural. Durante el transcurso del 
proceso de intensificación, se incrementan las cosechas en un mismo espacio y aumenta la producción y la productividad agrícola. Boserup elabora una visión optimista sobre la capacidad de las sociedades agrícolas de generar tecnologías más productivas sin deteriorar el medio ambiente. La intensificación del uso del suelo puede ayudar a reducir la deforestación, en la medida en que frena la expansión de formas extensivas de ocupación del espacio.

No obstante, debe tenerse en cuenta que la dinámica de cambios poblacionales en el VRAE es bastante más compleja y desigual que la descripción intentada por Boserup (1965). La información demográfica del VRAE demuestra que tal proceso de crecimiento poblacional no ha sido muy significativo en los últimos veinticinco años, al menos hasta el período de investigación entre 2001 y 2004. Ello se confirma al constatar la inexistencia de cambios en los niveles de densidad demográfica durante dicho período, y cuando ello ha ocurrido no ha sido muy relevante ${ }^{7}$. Básicamente, los cambios en el tamaño de la población han sido oscilantes y como consecuencia se han mantenido en veinte años en un mismo nivel. Prueba de ello es que la población de ambos distritos era en 1981 de 30757 habitantes y en 2004 de 30451 personas (INEI, 2009b; INEI, 2008; INEI, 2007; MINVIV, 2006a; MINVIV, 2006b) ${ }^{8}$. El valle ha sido escenario de conflictos militares, lo cual ha provocado transformaciones y oscilaciones en el tamaño poblacional, tales como emigraciones frente a la expansión de la violencia del narcotráfico y el senderismo9.

En ese sentido, no ha existido un incremento en la presión poblacional que pueda explicar los procesos de intensificación agrícola en el VRAE según la propuesta de Boserup. Los factores impulsores de la intensificación y deforestación son otros. Por un lado, las características del sistema de producción, y como

En los distritos de San Miguel, donde se localizan Palmapampa, y Santa Rosa, la densidad poblacional promedio en 1981 era de 24,11 habitantes por kilómetro cuadrado; en 1993, luego de diez años de conflictos con Sendero, la población disminuyó y así bajó la densidad a 22,88 habitantes por $\mathrm{km}^{2}$. En 2001, el momento inicial del estudio la población nuevamente se incrementó y así subió la densidad a 24,09 habitantes por $\mathrm{km}^{2}$, y en 2004, último año del estudio, la densidad volvió a bajar, aunque ligeramente, a 23,87 habitantes por $\mathrm{km}^{2}$ (INEI, 2009b; INEI, 2008; INEI, 2007; MINVIV, 2006a; MINVIV, 2006b). En todo el valle, en 2001, residía en el valle un total de 93608 personas mayoritariamente en poblados rurales (INEI, 2009a).

8 No cabe duda de que pudiera existir un cierto nivel de omisión censal resultado de la violencia existente en la región.

9 Un informe del INEI (2009a, p. 38) remarca que el impacto migratorio producto de la expansión de la coca en el VRAE no ha sido cuantitativamente importante, debido a que sigue siendo una región vinculada con niveles muy altos de violencia senderista y con el narcotráfico (INEI, 2009a, p. 38). 
componente fundamental el cultivo de la coca. Para comprender el impacto de los sistemas agrícolas descritos sobre los niveles de deforestación, se requiere entender el proceso de intensificación de uso del suelo en el VRAE. El índice de intensificación de uso del suelo es un indicador muy revelador de la manera como los agricultores ocupan el espacio según el tamaño del predio, dado que mide el peso relativo de las «purmas» o tierras en descanso frente a las hectáreas agrícolas en actividad. Ahora bien, a pesar de que no existe un incremento significativo de la densidad demográfica en los últimos veinticinco años en la región de estudio, sí se comprueba un patrón de intensificación en el uso del suelo. En el VRAE existe un claro predominio de predios cuya extensión es menor de las cinco hectáreas y que conforman casi dos tercios del total de las unidades agropecuarias. Los agricultores que conducen tales predios tienen un nivel de intensidad de uso del suelo de 0,85 , lo que significa que solo el $15 \%$ del área deforestada se encuentra en «purmas»/bosque secundario o en descanso (figura 1). Ello, no obstante, sin que se abandone la agricultura de rozo y quema. Entre las principales características de la agricultura migratoria se constata una clara asociación entre el tamaño del predio, la intensidad de uso del suelo y la tasa de deforestación.

Los predios agropecuarios relativamente más grandes en el VRAE, tal como sucede en el resto de las regiones amazónicas estudiadas, se caracterizan por un uso más extensivo del suelo mientras que los predios más pequeños tienen un uso más intensivo de uso del suelo (figura 1). Ello constituye una manifestación de la vigencia y reproducción de la agricultura migratoria basada en la tala y quema del bosque y rotación de suelos, dado que la intensidad en el uso del suelo en el VRAE depende en gran medida de la extensión de la parcela. Asimismo, en la medida que se reduce el tamaño de la parcela o finca, se incrementa la intensidad de uso del suelo y se reduce la tasa anual de deforestación (figura 1) (Bedoya, 2003; Bedoya y Ramírez, 2001).

La intensidad de uso del suelo tiene un impacto en la extensión global deforestada. Los predios que tienen un uso más extensivo del suelo poseen volúmenes de deforestación mucho más altos que los que tienen un uso más intensivo del suelo. Asimismo, los predios más extensos se caracterizan por un uso muy ineficiente de los recursos naturales. Por ejemplo, los predios cuyos índices de intensidad oscilan entre 0,3 y 0,4 por un lado, y 0,5 y 0,6 por otro lado, tienen entre 3,52 hectáreas y 3,75 hectáreas agrícolas en explotación respectivamente, y para ello han deforestado 9,92 y 6,71 hectáreas, en cada caso (tabla 1). Ello representa un inmenso desperdicio, y sobre todo la destrucción de recursos forestales y naturales en general. 
Figura 1. Intensidad del uso del suelo y tasa anual de deforestación en VRAEPerú según tamaño del predio 2001

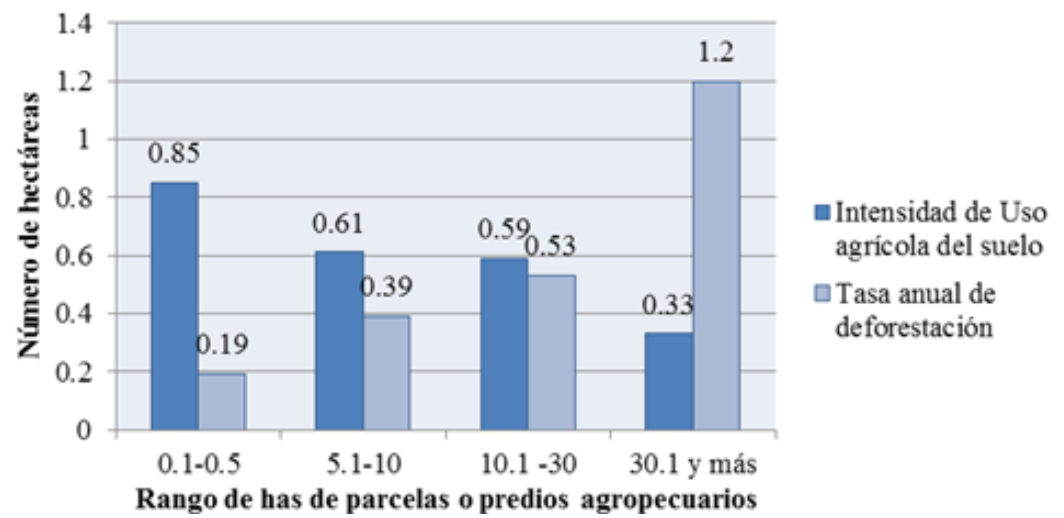

* La intensidad de uso del suelo se mide por la fórmula:

Cultivos permanentes + Cultivos transitorios

Cultivos permanentes + Cultivos transitorios + purmas o áreas en abandono

Fuente: Tablas 5 y 8 de Bedoya, 2003.

Tabla 1. Hectáreas agrícolas y en purmas (bosque secundario) y total deforestado, según intensidad de uso del suelo en el VRAE 2001

\begin{tabular}{cccccc}
\hline $\begin{array}{c}\text { Intensidad } \\
\text { de uso del } \\
\text { suelo }\end{array}$ & $\begin{array}{c}\text { Número } \\
\text { de casos } \\
\text { entrevistados } \\
\text { (porcentaje) }\end{array}$ & $\begin{array}{c}\text { Tamaño } \\
\text { promedio del } \\
\text { predio } \\
\text { (ha) }\end{array}$ & $\begin{array}{c}\text { Promedio } \\
\text { de hectáreas } \\
\text { agrícolas } \\
\text { cultivadas } \\
\text { (porcentaje) }\end{array}$ & $\begin{array}{c}\text { Promedio } \\
\text { de hectáreas } \\
\text { en purmas } \\
\text { o bosque } \\
\text { secundario } \\
\text { (porcentaje) }\end{array}$ & $\begin{array}{c}\text { Total de } \\
\text { hectáreas } \\
\text { deforestada } \\
\text { (porcentaje) }\end{array}$ \\
\hline 0,1 a 0,2 & - & - & - & - & - \\
0,3 a 0,4 & $12(10.0 \%)$ & 10,92 & 3,52 & 6,4 & 9,92 \\
0,5 a 0,6 & $26(21.7 \%)$ & 7,12 & 3,75 & 2,96 & $(100,0)$ \\
& & & $(56,00 \%)$ & $(44,00 \%)$ & $(100,0)$ \\
0,7 a 1,0 & $82(68.3 \%)$ & 4,32 & 3,56 & 0,37 & 3,93 \\
& $120(100,0)$ & & $(91,00 \%)$ & $(9,00 \%)$ & $(100,0)$ \\
\hline
\end{tabular}

Fuente: Base de datos del estudio Bedoya y Ramírez, 2001. 
Igualmente, en la zona estudiada existe un claro predominio de cultivos permanentes (cacao, coca y café) en el $69 \%$ de las familias, y en un $31 \%$ de estas predominan los cultivos anuales a los que se asocian los espacios en purma o bosques secundarios y la rotación de suelos (Bedoya, 2003; Bedoya y Ramírez, 2001). En los predios agrícolas con un uso más extensivo del suelo predominan los cultivos anuales, mientras que en aquellos con un uso más intensivo (que son mayoría) predominan los cultivos permanentes. Los cultivos que requieren una mayor rotación de suelos son los transitorios o anuales, y por ende, un ritmo de deforestación continua, aunque en extensiones más reducidas que el cacao o que otros cultivos permanentes (café). Dichos cultivos anuales son maíz, yuca, arroz bajo secano, frejol y otros. Son los que se asocian más a la denominada agricultura migratoria. Cada agricultor divide su predio en diversos sectores y en cada uno introduce uno o dos sembríos de forma asociada, incluso con plantaciones o cultivos permanentes. En situaciones normales, los rendimientos óptimos de los cultivos anuales o transitorios duran aproximadamente tres años, y luego los agricultores se trasladan a otras partes del predio, abandonando el primer terreno para su recuperación, y así sucesivamente van rotando dentro de la finca. Dicha dinámica sucede desde el principio de la ocupación de un lote de terrenos. Por lo mismo, el factor inicial de deforestación han sido los cultivos transitorios sembrados bajo la modalidad de agricultura de secano, que demandan una continua rotación de suelos.

Un aspecto importante es que los períodos de descanso del suelo duran más que los de cultivo. Es por ello que a la larga - y en especial en los predios más grandes, donde predominan los cultivos transitorios-, los espacios en descanso suman más que los terrenos en actividad. No obstante, la rotación de suelos también tiene un límite para aquellos predios más pequeños que no tienen suficiente espacio para el descanso o la recuperación de la fertilidad natural de los suelos. Ello sucede claramente en el VRAE, una región con una historia muy larga de colonización, uno de cuyos indicadores más importantes es la difusión de predios menores de cinco hectáreas. Los terrenos «empurmados» con menor potencial productivo, que están muy degradados o cansados, simplemente no son resembrados. El tiempo de descanso del suelo ya no es suficiente para garantizar una recuperación natural del suelo o del bosque. Es por ello que, al cabo de algunos años, los agricultores acumulan tierras abandonadas que no son cultivadas y que incluso son más extensas que las hectáreas cultivadas. Se produce lo que se denomina la «crisis del barbecho» (Smith et al., 1997, p. 10) ${ }^{10}$.

10 El fenómeno de la minifundización de la agricultura de la selva alta, los bajos rendimientos y la incapacidad de la agricultura migratoria basada en la rotación y el descanso de suelos 
En conclusión, las evidencias presentadas constituyen un claro indicador de que el sistema de rozo y quema (sembrío de cultivos anuales por dos o cuatro años, luego abandono de las tierras a modo de rotación de suelos, seguido del desmonte y quema de nuevos terrenos en bosque secundario), sigue constituyendo una práctica muy frecuente entre los agricultores en la región del VRAE.

\section{USO DE AGROQUÍMICOS SEGÚN TIPO DE CULTIVOS Y CRISIS DEL BARBECHO}

Como hemos señalado, en la zona de estudio predomina una agricultura de secano, que funciona bajo el régimen de lluvias y que provoca una continua deforestación. Este sistema no solo abarca a los cultivos transitorios o anuales sino también a los permanentes. En este último caso, la movilidad y rotación de suelos de los agricultores es menos frecuente, y sin embargo, debido al carácter medianamente empírico o tradicional del cuidado de las plantaciones de cacao, café y cítricos, los productores requieren extender sus cultivos para mantener la rentabilidad.

Ahora bien, el modelo de Boserup igualmente propone un proceso de transformación productiva y tecnológica de los sistemas agrícolas, donde el uso de energía renovable, basado en la regeneración natural de la tierra y ecosistemas, es paulatinamente reemplazado por energía no renovable, por ejemplo la agricultura mecanizada con un alto uso de insumos químicos. Cabe recalcar que en numerosas regiones de la Amazonía, en general, dicho modelo todavía puede aplicarse debido a la relativa disponibilidad de tierras y al bajo o casi nulo uso de energía no renovables entre los pequeños e incluso medianos agricultores migrantes (Guha y Martínez Alier, 1997, pp. 54-55). En ese sentido, la definición de Boserup sobre la intensificación de la agricultura es bastante más amplia que una simple reducción del espacio dedicado al descanso de los suelos o del tiempo dedicado a él. Dicho proceso no solo abarca esto último sino también la innovación e incorporación de nuevas técnicas de producción. En otras palabras, la intensificación agrícola no significa exclusivamente intensificación de uso del suelo. Ambos procesos pueden coincidir en el tiempo, pero cuando no ocurre así, las consecuencias pueden ser otras.

En el caso del VRAE, el aumento de la intensidad de uso del suelo no está acompañado de un cambio tecnológico generalizado. La mayor parte de las tierras

para seguir funcionado ha sido investigado durante las décadas de 1980 y 1990 por Barclay y Santos (1991). Los predios de menos de cinco hectáreas - e incluso de menos de diez en la Amazonía - pueden ser considerados como minifundios (Barclay y Santos, 1991, p. 31), debido a la pobreza de suelos y fragilidad del bosque tropical. 
agrícolas en actividad no reciben grandes cantidades de insumos modernos, salvo el caso del cultivo de la coca, sembrada en extensiones muy reducidas de las unidades agrícolas. Es decir, la dinámica de intensificación agrícola, que conduce a un incremento de la productividad a través de la aplicación de agroquímicos, es desigual y fundamentalmente limitada a las plantaciones de coca, sembradas para fines de narcotráfico. Por el contrario, en el VRAE el sistema agrícola vinculado con los cultivos legales es tan claramente tradicional que al momento del estudio, el $78 \%$ de los productores no usaba fertilizantes y el $90 \%$ tampoco recurría a insecticidas para el mantenimiento de sus cultivos legales. La tecnología se basaba en el uso del agua de lluvia y en la recuperación natural de la fertilidad del suelo mediante el barbecho o descanso del terreno (Bedoya, 2003).

El cultivo más importante en términos de extensión ha sido y sigue siendo el cacao cuyo sistema tecnológico es fundamentalmente tradicional. Conforme se extiende el predio, el área sembrada con cacao aumenta. Ello no sucede con el cultivo de la hoja de coca el que por razones de seguridad siempre se mantiene por debajo de la media hectárea. En la figura 2 se observa muy claramente dicha tendencia. Sin embargo, el cacao sembrado en esa extensión sirve como un complemento de ingresos y no como un sustituto de la coca. En ese sentido, numerosos agricultores —en especial los más jóvenes - buscan capitalizarse rápidamente sembrando coca, teniendo en cuenta que desde que siembran los plantones de cacao hasta la primera cosecha, deben transcurrir aproximadamente cuatro años. Es por ello que el cultivo de la coca atrae más atención y cuidado para los agricultores, dado que genera mayor rentabilidad y de manera más rápida.

En el año 2001, se calculaba que únicamente el 10\% de superficie sembrada con plantaciones de cacao era manejada con tecnología mejorada. En estos predios se obtenían rendimientos mayores de $1000 \mathrm{~kg} / \mathrm{ha} / \mathrm{año}$; un $30 \%$ de los predios eran conducidos con una tecnología media cuya productividad promedio oscilaba entre los 500 y $700 \mathrm{~kg} / \mathrm{ha} / \mathrm{año}$, y el $60 \%$ restante de productores utilizaba una tecnología tradicional con rendimientos promedios que oscilaban entre 300 y $450 \mathrm{~kg} / \mathrm{ha} / \mathrm{año}$. Cabe indicar que diez años después, en 2011, la productividad del cacao solo se situaba entre 400 y $600 \mathrm{~kg} / \mathrm{ha}$ (MINAGRO, 2012, pp. 11-13). En cualquier caso, dichos rendimientos eran inferiores al promedio nacional, que supera los 750 kilogramos por hectárea. La variedad criolla o tradicional del cacao es la que predominaba en la mayor parte de las plantaciones, la cual es una mezcla de híbridos procedentes de la estación de Tulumayo en Tingo María, y que fueron trasladadas al VRAE hace más de cuarenta años. Existen otras variedades clonadas, tales como el CCN-51, promovidas por el Programa de Desarrollo Alternativo y el Ministerio de Agricultura (MINAGRO, 2012, pp. 11-13). 
Figura 2. Promedio de hectáreas de coca, cacao y cultivos anuales según el tamaño del predio en el VRAE, 2001

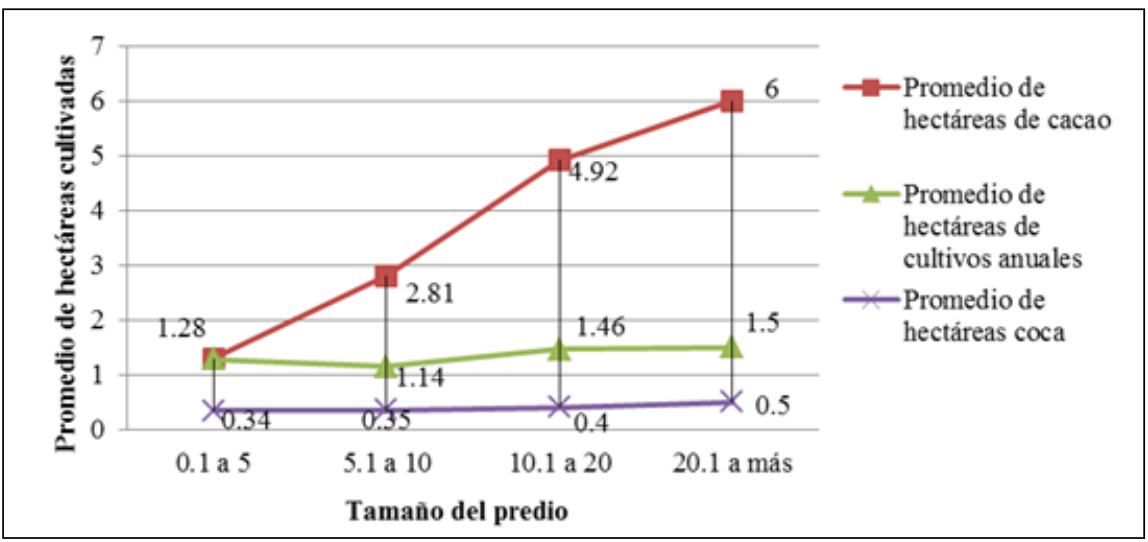

Base de datos del estudio Bedoya y Ramírez, 2001.

Si a ello se suma que, por un lado, la difusión de enfermedades tales como la Moniliasis, Phytoptora y Escoba de Brujas, provocaba que se pierda continuamente entre el $40 \%$ al 50\% de las cosechas (MINAGRO, 2012, pp. 11-13) y que, por otro lado, la condición de envejecimiento de más del $70 \%$ de las plantaciones de cacao se manifestaba en rendimiento decrecientes, es fácil entender la razón por la cual el cacao era un cultivo permanente pero con un mantenimiento muy poco tecnificado que obligaba a los productores a extender sus plantaciones para obtener un cierto nivel de rentabilidad (Bedoya, 2003; Bedoya y Ramírez, 2001; CARE, 2002). Una situación similar sucede con el café. La forma rudimentaria y poco sostenible de su mantenimiento hace que se abandonen los cafetales mucho antes de lo que sucede en otras regiones donde se maneja dicho cultivo de forma más intensiva y sostenible.

No obstante, la eventual ampliación, y luego el mantenimiento e intensificación de las plantaciones de cacao, enfrenta igualmente una serie de dificultades. Ante todo, el $61 \%$ de los productores del VRAE encuestados en el estudio de 2001 conducía predios cuyos tamaños oscilan entre 0,1 y cinco hectáreas (Bedoya, 2003). Si la estrategia de un agricultor fuera reemplazar los altos ingresos de la coca con el cacao, entonces va a requerir extensiones de cacao bastante mayores. Nuestro cálculo, entre 2001 y 2003, señalaba que para sustituir ingresos monetarios, por cada 0,39 hectáreas de coca eliminada, que es lo que en promedio tienen los agricultores entrevistados, se necesitaban 3,72 hectáreas de cacao, lo cual 
dependía naturalmente de los precios, costos, disponibilidad de mano de obra y el tipo de tecnología que en ese entonces era aplicada en ambos cultivos. Resulta claro que tal estrategia no era posible con predios relativamente pequeños ${ }^{11}$.

En todo caso, la alternativa de la deforestación no era muy costosa en el VRAE. Entre 2001 y 2004, los costos monetarios para deforestar o habilitar una hectárea giraban alrededor de 350 a 450 dólares, a la tasa de cambio de entonces, aproximadamente unos 770 a 880 soles. Tales costos podrían incluso reducirse a través del trabajo familiar no remunerado y otros factores que dependían del lugar, mes del año, costo de oportunidad del trabajador y el uso de motosierra o machete. Dicha explicación derivada de la economía clásica es válida, pero no es suficiente.

Si un agricultor del VRAE tiene la intención de extender sus cosechas de cacao durante varios meses al año y no solo en los meses pico, que van de abril a agosto, entonces tendría que realizar trabajos de deshierbe, poda y limpieza de forma constante y utilizar una variedad de agroquímicos. Ello aumentaría la productividad física pero también los costos. No obstante, los productores de cacao enfrentan una serie de problemas derivados de la pujante producción de coca en el VRAE. Sucede que el mantenimiento de las altamente lucrativas plantaciones de coca ha reorientado el capital y los otros factores de producción de la zona, tales como la mano de obra y la tierra, hacia dicho cultivo. En ese sentido, un indicador que comprobamos en el estudio realizado es que la escasez de mano de obra entre los productores afecta casi a un $100 \%$ de los que buscan reclutar trabajadores para los cultivos legales, sobre todo para el cacao y café, pero a menos del 5\% de estos para los cultivos de la coca. Ello se debe a que los agricultores cocaleros remuneran con jornales más elevados los trabajos específicos de la coca, en comparación con los otros cultivos.

Entre 2001 y 2004, los agricultores pagaban 0,40 soles el kilogramo de hoja de coca cosechada, lo que en un día muy productivo puede representar hasta tres veces el jornal de 8 soles que se paga en el cacao u otro cultivo comercial legal. Ello constituye un fenómeno muy frecuente en otras regiones cocaleras (Bedoya, 1999), como también en otros lugares donde un cultivo resulta siendo varias veces más rentable que aquellos otros cultivos que simultáneamente son sembrados en una misma región. Sin embargo, en el caso de la coca tal fenómeno es aún más acentuado, debido a su carácter ilegal y riesgoso. Veinte años antes en el Alto Huallaga, entre quienes tenían problemas de escasez de mano de obra, el 74\% eran agricultores

11 Por esa razón muchos de los productores sostenían que «prefieren media hectárea de coca y otra hectárea y media para su arroz, cafecito, maní, o cualquier otro para el pan llevar, entonces ya no tienen más terreno $[. .$.$] quieren pero no pueden».$ 
sin coca, frente al 26\% de los cocaleros (Bedoya, 1999, p. 220). Igualmente, los jornales pagados por los cocaleros eran tres veces más altos que los pagados por no cocaleros (p. 219). Un fenómeno semejante ocurrió en el Chapare en Bolivia a principios de la década de 1990, donde los costos para contratar mano de obra se incrementaron como resultado de la expansión cocalera (Painter y Bedoya, 1990).

En resumen, para el caso de los productores que conducen predios de más de 5 hectáreas, la estrategia del monocultivo del cacao sería factible, pero ello implicaría más esfuerzo de trabajo, puesto que se tendrían que trabajar extensiones mayores y obligaría a una mayor inversión de capital y a un mayor tiempo de cuidado y mantenimiento de las plantaciones de cacao para que sean más productivas. A ello se suma el riesgo económico de concentrarse en un solo cultivo. La alternativa de la intensificación a través del monocultivo del cacao no parece ser una opción razonable para los agricultores de la zona.

Figura distinta sucedía entre 2001 y 2004, en el cuidado de las pequeñas plantaciones de coca, cultivo que generaba en esos años el $47 \%$ de los ingresos monetarios. El 100\% de los agricultores entrevistados afirmó utilizar insumos modernos de manera frecuente y en grandes cantidades en las plantaciones de coca, generando tarde o temprano un impacto muy negativo en los suelos y en el ecosistema. Para mantener sus plantaciones, los agricultores recurrían a un cuantioso uso de fertilizantes, como la urea foliar o granular; pesticidas como Servin o Folidol y herbicidas como el Paraguat. Tal uso excesivo de fertilizantes nitrogenados aumenta la reproducción de insectos que dañan las plantaciones y causa la pérdida de las propiedades físicas, químicas y biológicas de los suelos (CDVRAE, 1996, p. 37). El cacao era el siguiente cultivo en términos de atención $\mathrm{y}$, sin embargo, nada comparable a lo que se realizaba en el mantenimiento del cultivo de la coca. Asimismo, cinco años atrás, en 1996, el estudio de Wachhlotz (1996, p. 14) menciona la misma tendencia sobre el uso de insumos. Apenas el 5\% de los productores usaba pesticidas y fertilizantes para los cultivos legales, mientras que para la coca, el 100\% de los productores los utilizaba para este cultivo.

Los cocaleros aumentan la densidad de las plantaciones de coca para elevar los rendimientos por unidad de terreno. La distancia entre cada planta es de aproximadamente 10 a 15 centímetros y de más o menos 35 centímetros entre líneas o también denominados «camellones». Ello permite alcanzar una densidad de 200000 plantas por hectárea, lo cual contrasta con las 40000 plantas de promedio en el valle de La Convención, en el Cusco (CDVRAE, 1996, p. 34). Por lo mismo, la producción por hectárea es cinco veces mayor en el VRAE en comparación a Quillabamba, en La Convención. Este sistema agrícola cocalero 
de uso sumamente intensivo del suelo reduce su vida productiva a solo seis o siete años, en comparación a los veinte años de vida que en promedio tienen las plantaciones en la selva de La Convención (CDVRAE, p. 34). Inicialmente, luego de un año de crecimiento, las plantaciones producen de manera continua durante tres a cuatro años un promedio de cien arrobas por hectárea al año, intercalados por períodos de poda o cachupas. Luego viene un período de descanso de nueve a doce meses y nuevamente se cosecha por dos o tres años, introduciendo cuantiosas cantidades de agroquímicos que dañan las propiedades físicas de los suelos (p. 37). Como resultado, la productividad suele bajar a menos de setenta a ochenta arrobas por hectárea al año, por lo cual los agricultores abandonan la plantación y a continuación deforestan otro terreno para iniciar el nuevo ciclo productivo. Ello puede suceder dentro del predio o en una zona más alejada. En ese sentido, existen razones técnicas y agronómicas que impiden que el agricultor extienda sus lotes de coca más allá de media hectárea o un poco más ${ }^{12}$.

A ello se suma el hecho de que la coca suele sembrarse en terrenos de fuerte pendiente, que al ser deforestados rápidamente, provocan erosión de los suelos. Tarde o temprano los agricultores cocaleros terminan abandonando sus plantaciones y deforestando bosque secundario o primario para reiniciar un ciclo agrícola con nuevas plantaciones de coca.

En su conjunto, el uso intensivo del suelo a través de la extrema densificación de las plantaciones y la intensificación agrícola a través del uso desmesurado de agroquímicos convierte a este sistema productivo en insostenible en pocos años. La práctica de rozo y quema para sembrar estos cultivos y luego el abandono de los mismos, conduce así al surgimiento de los terrenos abandonados. En 2001, de las 23000 hectáreas de coca sembradas en la zona, solo 8500 estaban siendo cosechadas y las restantes 15000 hectáreas se encontraban abandonadas o «empurmadas» (Glave y Valcárcel, 1998; Bedoya, 2001). Únicamente el 36\% de las plantaciones de coca se encontraba en producción. Asimismo, dos tercios de las hectáreas en descanso mostraban signos de erosión como consecuencia del lugar donde la coca había sido cultivada, especialmente en terrenos de topografía

12 Numerosos agricultores entrevistados argumentaron que: «a causa de los fertilizantes que la planta necesita, los suelos se empobrecen impidiendo el crecimiento posterior de otros cultivos. Así ante una caída del precio de la coca tampoco sería factible reemplazar rápidamente las áreas sembradas con otros productos. De esta forma no resulta conveniente tener mayores extensiones de este cultivo»; «los fertilizantes que se ponen a los cocales matan la tierra»; «con los años necesitas más y más fertilizantes para cosechar la coca y eso no es bueno para el suelo. Por eso terminas abandonando la misma coca para que crezca purma o monte». 
muy abrupta, pues una vez que se deforesta, la pérdida de nutrientes y de la capa fértil del suelo es muy rápida. Cabe indicar que la cifra total de 8500 hectáreas contrasta con la cantidad de hectáreas de coca que se encontraban activas en 1995, 1996 y 1997: 21 000, 16800 y 12600 hectáreas, respectivamente.

En los terrenos de coca abandonados se nota la presencia de helechos conocidos en la región como alpillo o alpillares, de 5 a $10 \mathrm{~cm}$, de diámetro, sumamente difíciles de trabajar en un deshierbo normal de la plantación (CDVRAE, 1996, pp. 43-44). La difusión de helechos constituye también un signo de degradación del suelo (MINAM 2015, p. 48). En numerosos casos estos helechos han invadido tierras agrícolas en actividad. En ese contexto, usualmente los costos de recuperación de las plantaciones son tan altos que son consideradas como irrecuperables. Ello a pesar de ser el cultivo más rentable de la región. En ese sentido muchas de las tierras que suelen denominarse en descanso o en barbecho, en proceso recuperación, son en realidad suelos abandonados por su alto nivel de erosión o degradación. Se trata de tierras donde el sistema de barbecho, o recuperación natural del suelo, ha entrado en crisis. En los predios de los cocaleros, el estudio comprobó en primer lugar, tal como se demuestra en la figura 3 , una relación muy visible entre tamaño del predio y las áreas en purmas o bosques secundarios. Cuanto más grande el predio mayor es también la extensión de purmas o bosque secundario. En ese sentido, un análisis basado en una correlación simple entre ambas variables arroja la cifra de 0,837, coeficiente sumamente alto. En un reciente documento (Bedoya 2016, ver figura 2) comprobamos que tal asociación existía también en todos los productores encuestados (cocaleros y no cocaleros) con un coeficiente de 0,75 , también muy alto. En el presente artículo, la figura 3 que incluimos se refiere exclusivamente a los cocaleros y la tendencia no es solo la misma sino que se acentúa.

En síntesis, el sistema de intensificación agrícola asociado al cultivo de la coca condujo a un abandono de miles de hectáreas de plantaciones de coca como consecuencia de la crisis del barbecho. Las purmas que se observan en aquellos años eran en algunos casos bosques secundarios, pero en muchísimos otros eran predios ocupados o invadidos por helechos o en general malas hierbas, lo que dificultaba la rápida recuperación de los suelos y el sembrío de nuevas plantaciones. Se trata de una situación insostenible para los agricultores cocaleros, que combina bajos rendimientos, crecimiento de malezas inmanejables y degradación de suelos. A ello obviamente se sumaba la caída de los precios internacionales de la cocaína entre 1996 y 1997 como resultado de las labores de interdicción y erradicación (Bedoya, 2001). Entre los agricultores no existía interés en 2001 por recuperar los terrenos «empurmados», por los costos y dificultades que ello implicaría. 
Figura 4. Tamaño del Predio y Hectáreas en Purma o Bosque Secundario (exclusivamente cocaleros del VRAE) 2001. Coeficiente 0,837

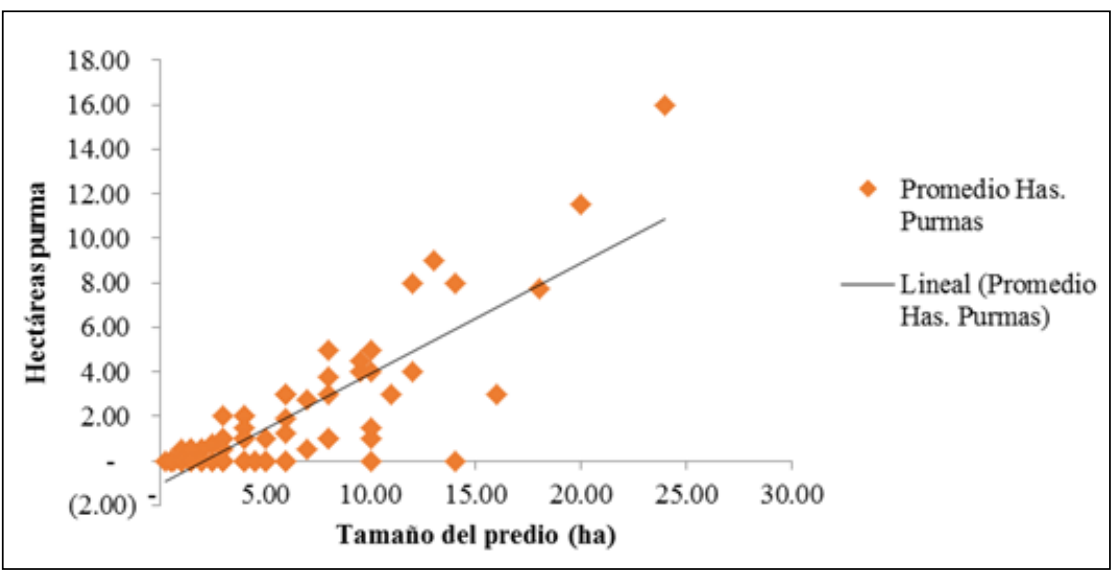

Fuente: Base de datos de Bedoya y Ramírez, 2001.

Finalmente, una alternativa frente al «cansancio de la tierra» o la «crisis del barbecho» es buscar nuevas tierras en zonas alejadas donde volver a reiniciar el ciclo tala, rozo y quema. En las entrevistas con los agricultores se encontró que por lo menos un 50\% conducía más de un predio en la zona del VRAE. Ello sucedía en especial entre los productores que conducían predios de menos de cinco hectáreas. En este caso los factores que son tomados en cuenta por los agricultores son otros. Lucich, Villena y Quinteros (2015, p. 160) han elaborado un modelo econométrico de carácter dinámico muy interesante sobre aquellos productores del VRAE que desean deforestar para instalar una nueva parcela. El modelo se centra en analizar el impacto de los costos de transporte en el proceso de toma de decisiones de los productores agrícolas del VRAE. Según los mencionados autores, la decisión de un productor en el VRAE de abrir una nueva chacra en un lugar distinto, que podría estar alejado, implica comparar los costos de mantenimiento de su antiguo predio, que incluyen el deshierbe, poda y fertilización, con los nuevos ingresos que se generarían a partir de los nuevos cultivos o plantaciones en la nueva parcela, deduciendo los nuevos gastos de transporte, los cuales incluyen el traslado de la mano de obra y el transporte de las cosechas al mercado (p. 159). Ahora bien, si por ejemplo, en el nuevo predio los costos de transporte son relativamente bajos y los precios pagados por la comercialización de la cosecha de café o cacao o coca son altos, entonces los agricultores probablemente optarán por deforestar e iniciar un ciclo productivo en una nueva 
parcela. Ello sucede no solo porque los ingresos y el correspondiente consumo familiar sería más alto, sino también porque podrían contratar trabajadores y así disponer de tiempo libre para el ocio (Lucich, Villena y Quinteros, 2015, p. 160). Todo ello ocurre dentro de un portafolio combinado de cultivos que se basa en productos altamente comerciales, tales como el cacao, café y la coca (p. 155).

El modelo dinámico de expansión y deforestación de la frontera en el VRAE propuesto por estos autores se reproduce en la medida en que los costos de transporte se hacen más bajos y competitivos, lo cual permite a los productores a trasladarse a otras zonas más alejadas y a deforestar. Es decir, la frontera seguirá expandiéndose en tanto que los costos de transporte disminuyan (p. 63). De acuerdo con las proyecciones realizadas por este estudio, tal dinámica provocará que en los próximos cien años se destruya, a partir de la introducción de plantaciones comerciales, entre el $40 \%$ y $60 \%$ de los bosques remanentes en el VRAE, proceso que tendría su mayor intensidad (el $80 \%$ de la deforestación) en los próximos 35 años (p. 63). Sin embargo, una situación distinta podría suceder si es que los agricultores del VRAE deciden abandonar el esquema de plantaciones legales comerciales y optan exclusivamente por la coca y diversos cultivos anuales. Resulta claro que en este caso, debido a la modalidad poco sostenible del cultivo de la coca y al sistema de producción extensivo de los cultivos transitorios, la agricultura migratoria de rozo y quema se expandirá aún más. Con ello se estaría condenando a estas poblaciones a una vida insegura, y además, se acentuaría el costo social y ambiental que supone un proceso de degradación y empobrecimiento de las tierras tropicales. Urge evaluar e implementar alternativas sostenibles de agricultura tropical para estas poblaciones que ya han vivido muchos años bajo el azote doble del terrorismo y el narcotráfico.

\section{COMENTARIOS FINALES}

En resumen, tal como hemos tratado de demostrar, los sistemas agrícolas en esta zona tropical son, a mediano plazo, totalmente insostenibles. La abundancia y persistencia de «purmas» o helechos en el VRAE se debe a la sobreutilización del suelo donde se cultiva la coca, al uso excesivo de insumos modernos o agroquímicos en dichas plantaciones, como también al mantenimiento tradicional o empírico del cultivo del cacao y otros sembríos transitorios. La alta correlación entre tamaño del predio y el área en «purmas» es un fiel reflejo de la «crisis del barbecho» en el VRAE. Los factores determinantes de esta crisis son, por un lado una intensificación agrícola en la coca que degrada el suelo y por otro, un uso muy 
extensivo del suelo sin cambio tecnológico en el caso de los cultivos legales. En ambos casos la consecuencia es la destrucción de los bosques, la deforestación y el empobrecimiento del suelo. El desarrollo agrícola en el VRAE no parece haber seguido el modelo optimista de Boserup (1965), que implica una intensificación más racional y sostenible.

Cabe indicar que las hectáreas en "purmas» bajas o altas o bosques secundarios no forman realmente parte de un barbecho forestal manejado, lo cual si sucede en sistemas agroforestales de numerosos productores indígenas. Las purmas o bosques secundarios son percibidas como espacios improductivos sin valor económico alguno, en espera de que se recuperen para nuevamente ser taladas. Los agricultores las definen como espacios futuros para ser reutilizados con fines agrícolas. Tampoco existe sobre ellas una percepción conservacionista y de regeneración del bosque. Se ha demostrado que los sistemas agrícolas que manejan los espacios empurmados o bosques secundarios pueden reducir las tasas de desbosque (Irvine, 1989). Ello no sucede entre los agricultores altoandinos en el VRAE. Existe una marcada diferencia entre tierras en actividad agrícola y tierras en descanso o empurmadas, lo cual no ocurre entre grupos indígenas, tampoco entre los denominados ribereños en el Perú o los caboclos en Brasil (Brondizio, 2009, p. 183; Cairns, 2015). En fin, la deforestación en el VRAE no genera el desarrollo de una agricultura sostenible e intensiva sino el surgimiento de una modalidad de producción altamente ineficiente y destructiva.

Por tanto, la intensificación del uso del suelo en el VRAE, especialmente entre los productores que poseen predios pequeños, no puede caracterizarse como una intensificación agrícola moderna sino más bien como un proceso de sobreutilización del uso del suelo sin cambios tecnológicos que signifiquen un manejo racional de los recursos. Mucho menos se trata de una agricultura o agroforestería sostenible. Ello genera rendimientos decrecientes, abandono de cultivos, traslado a otras zonas alejadas, más deforestación, y sobre todo, en numerosos casos, el refugio de los agricultores en el cultivo de la coca. Es por ello que el $64 \%$ de los cocaleros son productores que conducen predios agrícolas con menos de cinco hectáreas y que son precisamente los terrenos más sobreutilizados o que tienen los más altos índices de intensidad de uso del suelo.

En síntesis, el proceso de intensificación, acompañado del aumento en el uso de agroquímicos, es muy desigual dentro de las unidades agropecuarias en el VRAE. La intensificación agrícola ocurre fundamentalmente dentro de las plantaciones de la coca, mientras que el resto de los cultivos son sembrados y cuidados con técnicas básicamente extensivas de uso del suelo. Por dicho motivo, 
las altas tasas de deforestación se centran en estos últimos cultivos y no en la coca (Bedoya, 2003). El tema es que la coca solo ocupa un espacio comparativamente muy reducido de cada unidad agrícola frente al resto de cultivos. No obstante, la intensificación agrícola en las plantaciones de coca provoca el freno a una agricultura sostenible al interior de los predios de los agricultores del VRAE y promueve el desarrollo de un sistema productivo muy extensivo entre los cultivos legales y altamente destructivo del bosque.

\section{REFERENCIAS BIBLIOGRÁFICAS}

Aldrich Stephen, Robert Walker, Eugenio Arima, Marcellus Caldas, John Browder y Stephen Perz (2006). Land-Cover and Land-Use Change in the Brazilian Amazon: Smallholders, Ranchers and Frontier Stratification. Economic Geography, 82(3), 265-288. https://doi.org/10.1111/j.1944-8287.2006.tb00311.x

Amazon Conservation Association (ACA) y Conservación Amazónica (ACCA) (2015). Deforestación de gran escala vs. pequeña escala en la Amazonia peruana. Lima: MAAP - Monitoring of the Andean Amazon Project (Proyecto de Monitoreo de los Andes Amazónicos http://maaproject.org MAAP \#32.

Aramburú Carlos (1984). Problemática social en las colonizaciones. En Población y colonización en la alta Amazonía peruana (pp. 65-81). Lima: Consejo Nacional de Población y CIPA.

Aramburú, Carlos y Eduardo Bedoya (1986). Poblamiento y uso de los recursos en la Amazonía alta; el caso del Alto Huallaga. En Carlos Mora y Carlos Aramburú (eds.), Desarrollo amazónico: una perspectiva latinoamericana. Lima: Centro de Investigación y Promoción Amazónica (CIPA) e Instituto Andino de Estudios en Población y Desarrollo (INANDEP).

Banco Mundial (2000). Perú. Environmental Issues and Strategic Options. Informe Número 20700-PE.

Barclay, Frederica y Fernando Santos (1991). El minifundio en la selva alta. Debate Agrario, 42, 31-56.

Bedoya Garland, Eduardo (1982). Colonizaciones a la ceja de selva a través del enganche: el caso SAIPAI en Tingo María. En Carlos Aramburú, Eduardo Bedoya y Jorge Recharte (eds.), Colonización en la Amazonía. Lima: Centro de Investigación y Promoción Amazónica (CIPA).

Bedoya Garland, Eduardo (1999). Coca Expansion, Labor Scarcity, and Deforestation in Upper Huallaga, Peru. En Richard Bilsborrow y Daniel Hogan (eds.), Population and Deforestation in the Humid Tropics. Lieja: International Union for the Scientific Study of Population (USSP). 
Bedoya Garland, Eduardo (2003). Las estrategias productivas y el riesgo entre los cocaleros del valle de los ríos Apurímac y Ene. En Carlos Aramburú y Eduardo Bedoya Garland (eds.), Amazonía. Procesos demográficos y ambientales. Lima: Consorcio de Investigación Económica y Social (CIES).

Bedoya Garland, Eduardo (2016). La deforestación y la tragedia de los comunes entre los cocaleros del VRAE: 2001-2013. Espacio y Desarrollo, 28, 75-101. https:// doi.org/10.18800/espacioydesarrollo.201601.004

Bedoya Garland, Eduardo y Lorien Klein (1996). Forty Years of Political Ecology in the Upper Peruvian Forest: The Case of Upper Huallaga. En Leslie E. Sponsel y Thomas Headland, Robert G. Bailey (eds.), Tropical Deforestation. The Human Dimension (pp. 165-186). Nueva York: Columbia University Press.

Bedoya Garland, Eduardo y Walter Ramírez Eslava (2001). Estrategias Productivas y Laborales de los Agricultores Cocaleros y No Cocaleros de Santa Rosa y Palmapampa. Base de datos de consultoría para el Consorcio de Investigación Económica y Social (CIES)/Winrock. Lima.

Bilsborrow, R. (1997). Population Dynamics and Deforestation in Latin America: Research findings and policy issues. Nidi Hostee Lecture Series, 4. La Haya.

Boserup, Ester (1965). The Conditions of Agricultural Growth. The Economics of Agrarian Change under Population Pressure. Chicago: Aldine.

Brondizio, Eduardo (2009). Agriculture Intensification, Economic Identity, and Shared Invisibility in Amazonian Peasantry: Caboclos and Colonists in Comparative Perspective. En Amazon Peasant Societies ern a Changing Environment. Political Ecology, Invisibility and Modernity in the Rain Forest (pp. 181-214). São Paulo: Springer.

Cairns, Malcom (2015). Shifting cultivation and environmental change: indigenous people, agriculture and forest conservation. Nueva York: Routledge

Caldas, Marcellus, Robert Walker, Eugenio Arima, Stephen Perz, Stephen Aldrich y Cynthia Simmons (2007). Theorizing Land Cover and Land Use Change: The Peasant Economy of Amazonian Deforestation. Annals of the Association of American Geographers, 97(1), 86-110. https://doi.org/10.1111/j.1467-8306.2007.00525.x

CARE PERU (2002). Estudio de base, elaboración de una metodología de monitoreo y evaluación para el PDA. Consultoría elaborada por Eduardo Bedoya, Zulema Burneo, Walter Ramírez y Nilda Chia. Documento interno.

Chevalier, Jacques (1982). Civilization and the Stolen Gift. Capital, King and Cult in Eastern Peru. Toronto: University of Toronto Press.

Comité de Desarrollo del Valle del Río Apurímac y el Ene (CDVRAE) y Proyecto AD/ PER/939-UNDCP/UNDOPS (1996). Valle del Río Apurímac y el Ene. Bases para su desarrollo integral. Pichari. 
Deadman, Peter, D. Robinson, E. Moran y E. Brondizio (2004). Colonist household decision making and land-use change in the Amazon Rainforest: an agent based simulation. En Environment and Planning B: Planning and Design, 4, 693-703.

Diez Hurtado, Alejandro (2003). Los desplazados en el Perú. Lima: CIR-PAR.

Durand Guevara, Anahí (2005). El movimiento cocalero y su (in)existencia en el Perú. Itinerario de desencuentros en el río Apurímac. Bulletin de l'Institut Français d'Etudes Andines (Boletín del Instituto Francés de Estudios Andinos), 34(1), 103-126. Lima. https://doi.org/10.4000/bifea.5651

Espinoza de Rivero, Óscar (2009). ¿Salvajes opuestos al progreso?: aproximaciones históricas y antropológicas a las movilizaciones indígenas en la Amazonía peruana. Anthropologica, XXVII(27), 123-168.

Glave, Manuel y Marcel Valcárcel (1998). Bases para la Estrategia de Desarrollo Local Sostenible de Palmapampa, Valle del Río Apurímac. Consultoría para Acción Agraria http://www.grade.edu.pe/upload/publicaciones/archivo/download/pubs/ paper-desarrollo-apurimac-mg-EIG051.pdf.

Gómez de la Torre Sara, Susana Anda y Eduardo Bedoya Garland (2017). Procesos políticos y factores estructurales de la deforestación en la Amazonía ecuatoriana. El caso de Tena en Ecuador. Espacio y Desarrollo, 29, 7-36. http://dx.doi. org/10.18800/espacioydesarrollo.201701.001

Guha, R. y Juan Martínez Alier (1997). The Merchandising of Biodiversity. Varieties of Environmentalism. Londres: Earthscan.

Instituto Nacional de Estadística e Informática (INEI), Perú (2009a). Perú, migraciones internas 1997-2003. Lima: Dirección Técnica de Estadísticas e Indicadores Sociales.

Instituto Nacional de Estadística e Informática (INEI), Perú (2009b). Estimaciones y proyecciones de población por sexo, según departamento, provincia y distrito, 2000, 2015. Boletín Especial No 18. Lima.

Instituto Nacional de Estadística e Informática (INEI), Perú (2008). Primeros resultados. Perú: crecimiento y distribución de la población 2007. Lima.

Instituto Nacional de Estadística e Informática (INEI), Perú (2007). Base de datos por distrito, Censo 2007. Lima.

Li Suárez, Diana (2009). Ayacucho: análisis de la situación en población. Lima: Fondo de Población de las Naciones Unidas (UNFPA) y Consorcio de Investigación Económica y Social (CIES).

Lucich, Iván M., Mauricio G. Villena, y María José Quinteros (2015). Transportation costs, agricultural expansion and tropical deforestation: Theory and evidence from Peru. Ciencia e Investigación Agraria, 42(2), 153-169. https://doi. org/10.4067/s0718-16202015000200003 
Mayer, Enrique (2004). Casa, chacra y dinero. Economías domésticas y ecología en los Andes. Lima: Instituto de Estudios Peruanos.

Martínez, P. (2010). Informe forestal. Proyecto Mesozonificación Ecológica y Económica para el Desarrollo Sostenible del Valle del Río Apurímac - VRA. Iquitos: Instituto de Investigaciones de la Amazonía Peruana. Programa de Cambio Climático, Desarrollo Territorial y Ambiente - PROTERRA.

McCracken, D., D. Siqueira, E. Morán y E. Brondizio (2002). Land Use Patterns on an Agricultture Frontier in Brasil: Insights and examples from a demographic perspective. En Charles Wood y R. Porro (eds.), Land Use and Deforestation in the Amazon (pp. 162-192). Florida: University Press of Florida. Gainesville.

Ministerio de Agricultura (MINAGRO), Perú (2012). Programa Agrovraem. Plan de Intervención a Mediano Plazo (Periodo 2013-2016) del Ministerio de Agricultura en el Valle de los Ríos Apurímac, Ene y Mantaro. Lima.

Ministerio de Medio Ambiente (MINAM) Perú, SERFOR, Programa Bosques, Ministerio de Relaciones Exteriores, Ministerio de Cultura, Ministerio de Economía y Finanzas, Ministerio de Agricultura y Riego (MINAGRO) et al. (2015). «Hacia una estrategia sobre bosques y cambio climático». Documento preliminar. Lima.

Ministerio de Medio Ambiente (MINAM) Perú, SERFOR, Bosques, Ministerio de Agricultura y Riego (MINAGRO) et al. (2015a). Informes temáticos del sector ambiente, bosques. Lima: Programa Nacional de Conservación de Bosques.

Ministerio de Medio Ambiente (MINAM), Ministerio de Agricultura y Riego (MINAGRO), Programa de Naciones Unidas para el Desarrollo (PNUD) (2009). Causas y medidas de mitigación a la deforestación en áreas críticas de la Amazonía peruana y a la emisión de gases de efecto de invernadero. Lima.

Ministerio de Vivienda, Construcción y Saneamiento (MINAVIV) Perú (2006a). Plan de Desarrollo Urbano, San Miguel. 2006-2015.

Ministerio de Vivienda, Construcción y Saneamiento (MINAVIV) Perú (2006b). Plan de Desarrollo Urbano, Santa Rosa. 2006-2015

ONERN (Oficina Nacional de Recursos Naturales) (1982). Clasificación de las tierras del Perú. Lima,

Painter, M. E. Bedoya Garland. (1990). Socioeconomic Issues in Agricultural Settlement and Production in Bolivia's Chapare Region. Working Paper 70. Binghamton, NY: Institute for Development Anthropology.

Perz, Stephen G., Carlos Aramburú y Jason Bremmer (2002). The Changing Social Contexts of Deforestation in the Brazilian Amazon. Social Science Quarterly, 83(1), 35-52. https://doi.org/10.1111/1540-6237.00069 
Perz, Stephen G., Carlos Aramburú y Jason Bremmer (2005). Population, Land Use and Deforestation in the Pan Amazon Basin: A comparison of Peru, Brazil. Bolivia, Colombia, Ecuador, Perú y Venezuela. Environment, Development and Sustainability, 7, 23-49 https://doi.org/10.1007/s10668-003-6977-9

Putzel, Peter Cronkleton, Anne Larson, Miguel Pinedo-Vásquez, Omar Salazar y Robin Sears (2013) Producción y comercialización de bolaina (Guazuma crinita), una especie amazónica de rápido crecimiento. Un llamado a la adopción de un marco de políticas que apoye los medios de vida Louis. Brief, 25. Octubre. Iquitos.

Ramírez Eslava, Walter (2001). Análisis económico de los agricultores del valle del río Apurímac-Ene. Lima: Consultoría para el Consorcio de Investigación Económica y Social (CIES) y Winrock.

Recharte, Jorge (1982). Prosperidad y pobreza en la agricultura de la ceja de selva: El valle de Chanchamayo. En Carlos Aramburú, Eduardo Bedoya y Jorge Recharte (eds.), Colonización de la Amazonía. Lima: CIPA.

Rudel, Thomas K., Diane Bates y Rafael Machinguiashi (1998). Is There a Forest Transition? Deforestation, Reforestation, and Development. Rural Sociology, 63(4), 533-552. https://doi.org/10.1111/j.1549-0831.1998.tb00691.x

Rudel, Thomas K., Diane Bates y Rafael Machinguiashi (2002). A Tropical Forest Transition? Agricultural Change, Out-Migration, and Secondary Forests in the Ecuadorian Amazon. Annals of the Association of American Geographers, 92(1), 87-102. https://doi.org/10.1111/1467-8306.00281

Sala y Vila, Nuria (2001). Selva y Andes: historia de una región en la encrucijada. Madrid: Consejo Superior de Investigación Cientifica - CSIC.

Smith, Joyotee, César Sabogal, Wil de Jong y David Kaimowitz (1997). Bosques secundarios como recurso para el desarrollo rural y la conservación ambiental en los trópicos de América Latina. Occasional Paper, 13. Bogor: Centro para la Investigación Forestal Internacional. Diciembre.

UNOPS (Oficina de Servicios para Proyectos de las Naciones Unidas) (1997). «Programa de base de los beneficiarios del Proyecto AD/PER/95/939». Documento interno. Lima.

Wachholtz, R., (1996). Economía de los sistemas agrícolas en el Valle Apurímac, Perú. Informe para el PNUFID. Lima.

Watters, R. F. (1971). La agricultura migratoria en América Latina. Cuadernos de Fomento Forestal, 17. Roma: FAO.

Yanggen, David (1999). Agriculture's Impact on Deforestation in the Peruvian Amazon. An Analysis of Policy options to Promote Sustainable Alternatives in the Post Liberalization Era. Lima: ICRAF-Perú. 